\title{
Superconducting interface for a DC circuit breaker
}

DOI:

10.1049/cp.2016.0349

\section{Document Version}

Accepted author manuscript

Link to publication record in Manchester Research Explorer

\section{Citation for published version (APA):}

Pei, X., Smith, S., \& Barnes, M. (2016). Superconducting interface for a DC circuit breaker. In 8th IET International Conference on Power Electronics, Machines and Drives (PEMD 2016): Glasgow, UK 19-21 April 2016 https://doi.org/10.1049/cp.2016.0349

\section{Published in:}

8th IET International Conference on Power Electronics, Machines and Drives (PEMD 2016)

\section{Citing this paper}

Please note that where the full-text provided on Manchester Research Explorer is the Author Accepted Manuscript or Proof version this may differ from the final Published version. If citing, it is advised that you check and use the publisher's definitive version.

\section{General rights}

Copyright and moral rights for the publications made accessible in the Research Explorer are retained by the authors and/or other copyright owners and it is a condition of accessing publications that users recognise and abide by the legal requirements associated with these rights.

\section{Takedown policy}

If you believe that this document breaches copyright please refer to the University of Manchester's Takedown Procedures [http://man.ac.uk/04Y6Bo] or contact uml.scholarlycommunications@manchester.ac.uk providing relevant details, so we can investigate your claim.

\section{OPEN ACCESS}


This paper is a postprint of a paper submitted to and accepted for publication by, and is subject to Institution of Engineering and Technology Copyright. The copy of record is available at IET Digital Library

\title{
Superconducting Interface for a DC Circuit Breaker
}

\author{
X Pei, A C Smith, M Barnes \\ School of Electrical and Electronic Enginerring, University of Manchester, M13 9PL, UK \\ email:xiaoze.pei@manchester.ac.uk
}

Keywords: DC circuit breaker, interface, mechanical switch, semiconductor, superconductor.

\begin{abstract}
High voltage direct current (HVDC) circuit breakers are a key technology to enable fault management for multi terminal DC (MTDC) networks. DC circuit breakers using superconductors for current limiting have been proposed previously and experimentally tested at low voltage levels. Superconductor materials are ideal for DC networks: they do not incur losses operating with pure DC current. This paper will focus on the interface between the superconductor element and the other elements of the breaker, i.e., the mechanical switch and semiconductor elements. A $10 \mathrm{kV} \mathrm{DC}$ circuit breaker will be developed based on the optimized interface and control strategy.
\end{abstract}

\section{Introduction}

The development of renewable energy generation is vital to providing energy security and reducing the environmental impact of fossil fuels. Offshore wind energy plays an important role in enabling the UK to meet its 2020 renewable energy targets [1]. It is therefore essential to accommodate and integrate offshore renewable energy by using a costeffective transmission network. High voltage direct current (HVDC) transmission systems using voltage source converter (VSC) offer great potential for long distance bulk power delivery. Multi terminal DC (MTDC) networks and meshed DC grids further improve system stability, reliability and security [2, 3]. HVDC circuit breakers are a critical technology for managing faults in MTDC networks. DC current breaking however is much more challenging than $\mathrm{AC}$ systems because there is no natural current zero-crossing to isolate the fault [4]. The rise rate of short circuit currents in DC networks is also much higher due to the lower system impedances. Hybrid HVDC circuit breakers comprised of mechanical switches, semiconductors and varistors have been investigated by several manufactures $[5,6]$. The conduction losses of the solid-state semiconductors however still dominate the DC circuit breaker losses. A faster and costeffective DC circuit breaker which enables direct fault isolation for MTDC networks is urgently required.

Recently DC circuit breakers using superconductors for current limiting have been proposed and tested at $400 \mathrm{Vdc}$ [7]. Superconductor materials are ideal for DC networks: they do not incur losses operating with pure DC current, and they naturally transition to a high resistance once the fault current exceeds the critical current of the superconductor. This process is also called superconductor quench. The critical current of the superconductor depends on the type of superconductor and the operating temperature.

This paper will focus on the interface between the superconductor element and the other elements of the breaker, i.e., the mechanical switch and the semiconductors. Fault protection devices such as superconducting circuit breakers and superconductor fault current limiters (SFCLs) for both $\mathrm{AC}$ and DC system are reviewed. These systems are divided into two categories depending on the control of the mechanical switch. The mechanical switch driven by an electromagnetic repulsion mechanism does not require an external power supply and trigger signal; however, it might be affected by the magnitude of the fault current and also difficult to coordinate with an auto-reclosing function. The mechanical switch controlled by an independent actuator provides greater flexibility. An AC SFCL integrated with a vacuum interrupter was investigated experimentally at the University of Manchester. The magnitude of the superconductor coil voltage was compared with a pre-set threshold voltage and used to automatically trigger the mechanical breaker actuator. Separating the actuator supply from the fault current provides the greatest system operational flexibility. External triggering signals can also be brought in if necessary to provide full control of the operation of the SFCL/actuator unit.

This paper will cover a detailed comparison of the above prototypes and select which is more suitable for a DC circuit breaker. This paper will also look at the system requirements (eg external trigger signal, semiconductor) and examine the circuit breaker trigger signal specification and the impact on the electrical and mechanical element design. A $10 \mathrm{kV} \mathrm{DC}$ circuit breaker will be developed based on the optimized interface option and control strategy. This would represent a competitive candidate DC circuit breaker for MTDC networks.

\section{SFCL to DC circuit breaker interface}

For medium and high voltage applications, vacuum and sulphur hexafluoride $\left(\mathrm{SF}_{6}\right)$ have already replaced the previous air and oil solutions and have become the most widely used types of circuit breaker. In this paper, the mechanical switches refer to either vacuum interrupters or $\mathrm{SF}_{6}$ circuit 
breakers. The control is similar for both vacuum interrupter and $\mathrm{SF}_{6}$ circuit breaker apart from the actuator/operating system.

\subsection{Mechanical switch driven by an electromagnetic repulsion mechanism}

In this section, the SFCL system with a mechanical switch powered by an electromagnetic repulsion mechanism is discussed. A hybrid AC SFCL has been developed in $[8,9]$. The experimental diagram is shown in Figure 1. The superconductor and the vacuum interrupter are connected in series and then in parallel with a coil. If a fault occurs, the superconductor element transitions into a high resistance. The current is transferred to the parallel coil. The current in the parallel coil drives the electromagnetic repulsion mechanism to open the vacuum interrupter. This type of SFCL demonstrated successful operation and fast recovery of the superconductor.

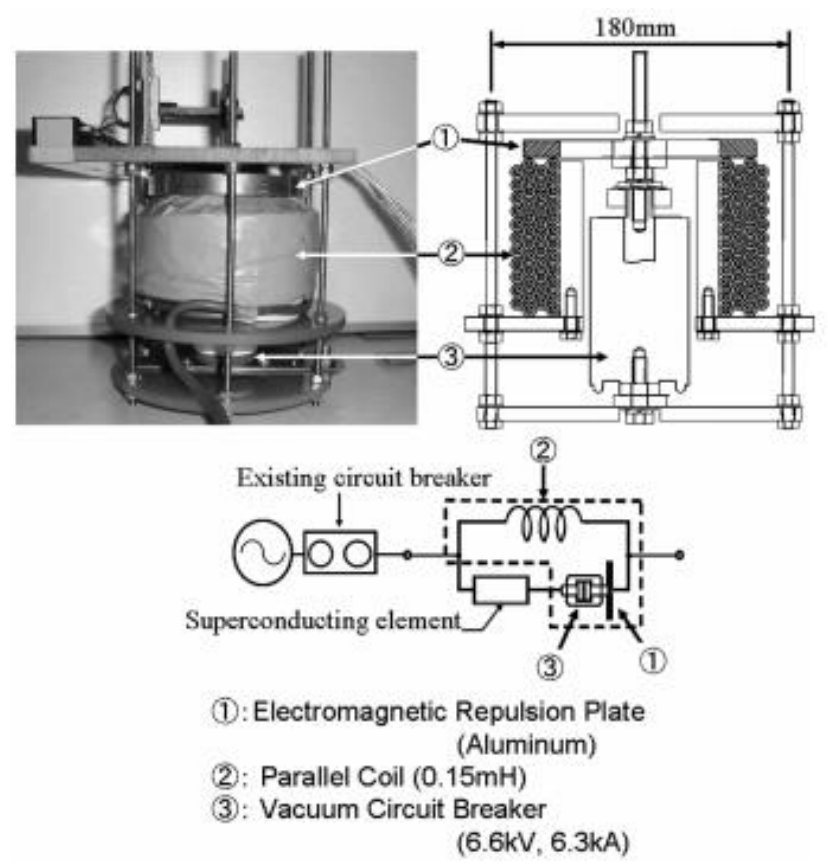

Figure 1: Hybrid AC SFCL with vacuum interrupter driven by electromagnetic repulsion mechanism [8]

Another hybrid AC SFCL has been designed (Figure 2) and developed for the Korea Electric Power Corporation (KEPCO) $[10,11]$. The superconductor coil is connected in series with a vacuum interrupter and in parallel with a driving coil. As the superconductor coil becomes resistive during a fault, current flows through the driving coil, and the field produced by the coil current activates the fast switch that causes the current to be diverted into a reactor. The reactor provides the limitation action throughout the remainder of the fault event. In operation, the fast switch is basically a plunger with a switch on either end that commutates the line current. The driving coil exerts force on the repulsion plate that engages the plunger to activate the limiting reactor [11].

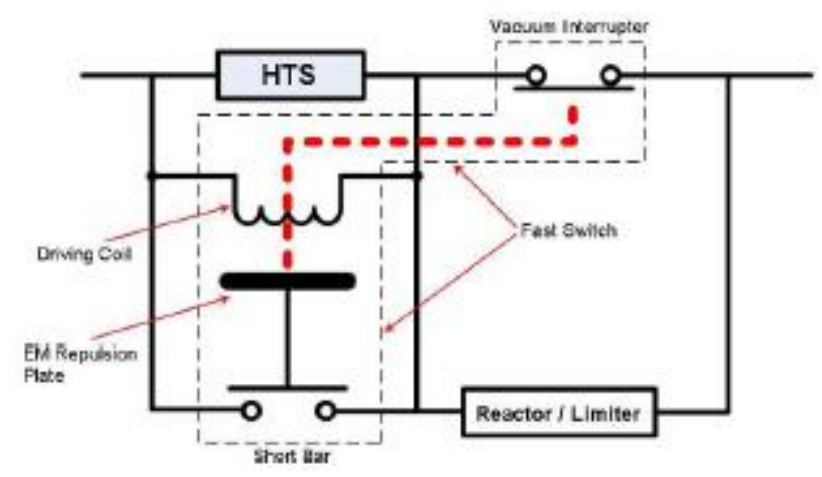

Figure 2: Hybrid AC SFCL [10]

Advantages and disadvantages of the AC SFCL system with a vacuum interrupter powered by an electromagnetic repulsion mechanism are summarised as follows.

Advantages:

- Compact structure with reduced superconductor material and cryogenic volume compared with a resistive SFCL.

- Automatic operation once fault occurs and neither external power supply nor external trigger signal required. This greatly simplified the system interface requirement.

Disadvantages:

- The operation of the vacuum interrupter might be affected by the fault current level because the electromagnetic repulsion mechanism is powered by the fault current.

- The vacuum interrupter might close again before the fault is cleared. When the fault current level is reduced, the electromagnetic repulsion mechanism might not provide enough force and the vacuum interrupter might close again before the fault is cleared.

- It might also be difficult to coordinate this with an auto-reclosing function. No external control can be introduced, which significantly reduces the system controllability.

\subsection{Mechanical switch driven by independent actuator}

A mechanical switch driven by electromagnetic repulsive force derived from the fault current has been discussed for controlling the mechanical switch under different fault conditions and auto-closing coordination. This section discusses the system with a mechanical switch operated by an independent actuator / operating mechanism.

A high-speed interrupter with a solenoidal coil was used in a three-phase AC SFCL. Figure 3 presents the experiment circuit diagram of the SFCL operating system with the solenoid driving coil. The circuit is similar to the first hybrid AC SFCL except that the vacuum interrupter is operated by a solenoidal coil. A current transformer is used to monitor the 
current level in the AC network and the overcurrent signal is send to the thyristor control system. The solenoidal coil actuator is supplied by a separate AC source. The operating efficiency of the solenoidal coil is low however because there is no latching function.

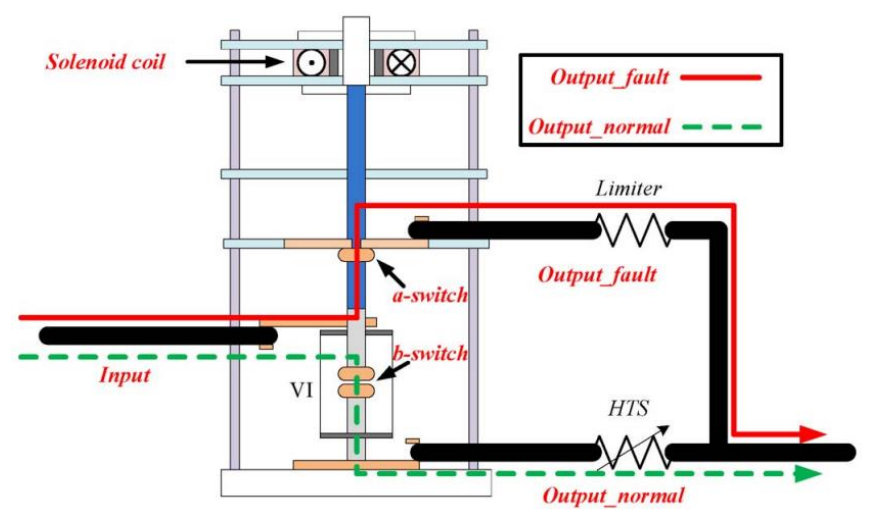

Figure 3: SFCL system with solenoid driving coil [12]

A $138 \mathrm{kV}$ hybrid SFCL design concept has also been proposed and shown in Figure 4. Initially the superconducting coil provides a low impedance current path. Once a fault is detected by the protection and DAQ system, the hybrid design utilizes a fast operating switch to remove the superconductor from the circuit during quench, leaving a reactor in line to limit the fault current.

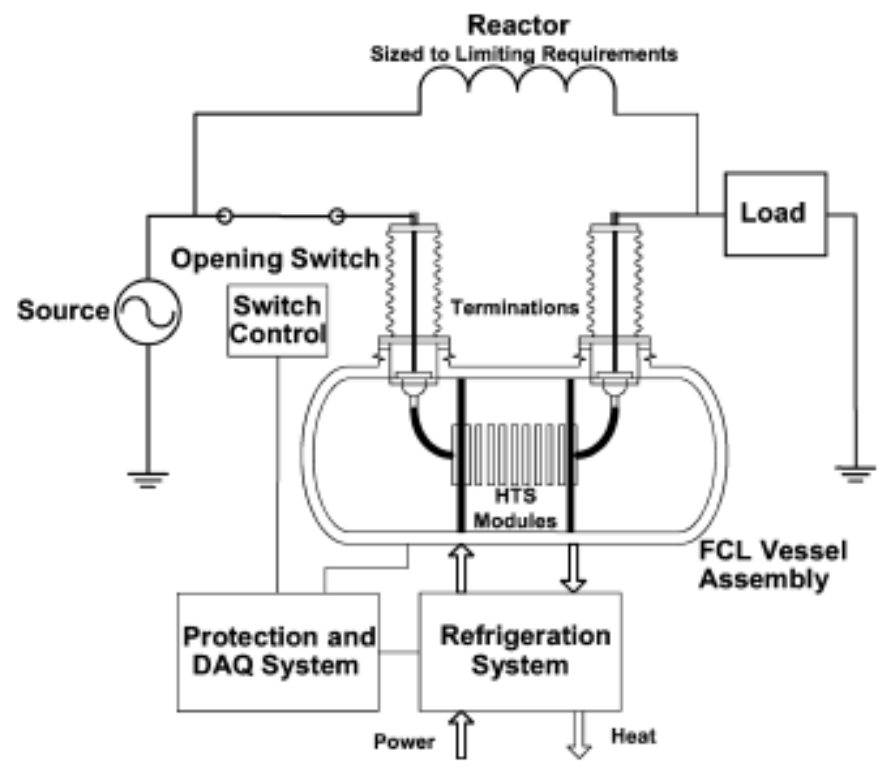

Figure 4: $138 \mathrm{kV}$ hybrid SFCL [10]

Recently a DC circuit breaker using a superconductor for current limiting has been proposed and tested at $400 \mathrm{Vdc}$. Figure 5 shows the structure of the DC circuit breaker, which comprises a current limiting part (superconductor in parallel with a resistor) and an interrupting part (a conventional gas circuit breaker). The gas circuit breaker and its actuator are shown in Figure 6. During normal operation, the current flows through the superconductor and the gas circuit breaker with negligible losses. Once a fault occurs, the superconductor transitions into a high resistance when the fault current exceeds the superconductor critical current and limits the fault current as quickly as 1 millisecond. The gas circuit breaker then opens at a low current level and directly interrupts a small DC current (less than $200 \mathrm{~A}$ ). A $\mathrm{ZnO}$ arrester is used to absorb the residual energy after interruption.

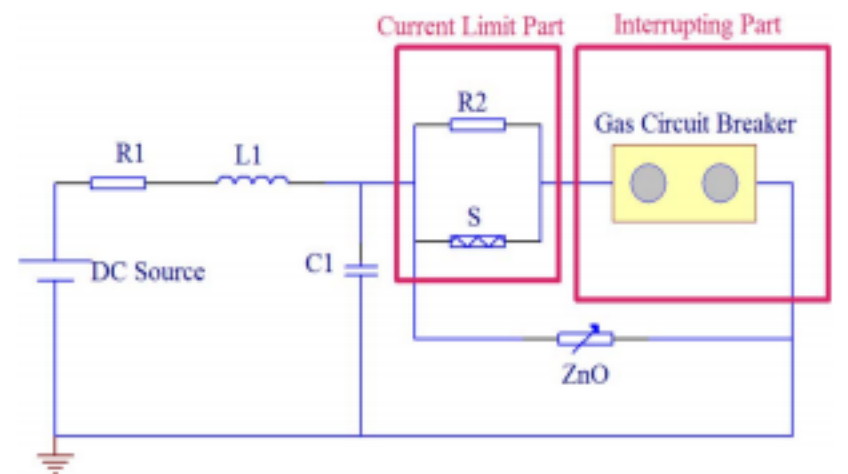

Figure 5: Structure of the DC circuit breaker [7]

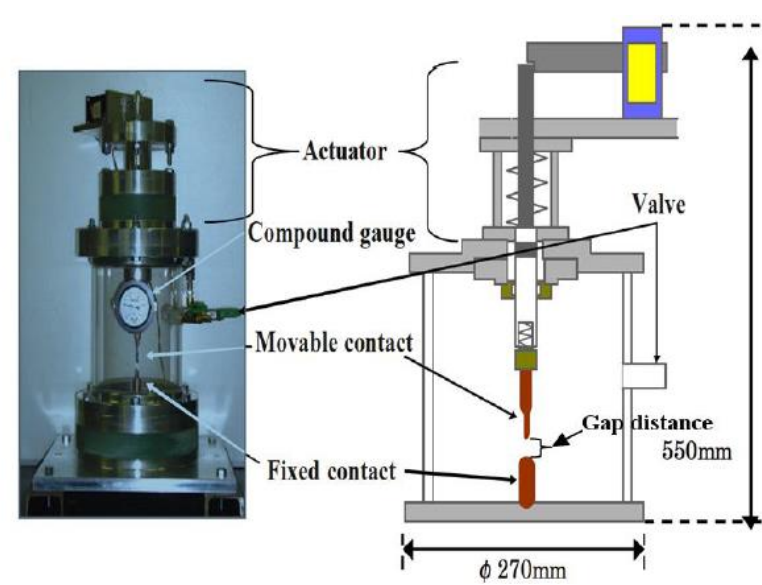

Figure 6: DC circuit breaker mechanical component [7]

The advantages of a system using a mechanical switch driven by an independent actuator are:

- Compact structure with reduced superconductor and cryogenic volumes compared to a resistive SFCL.

- The operation of the actuator/ vacuum interrupter is independent from the fault current level. This ensures fast operation under any fault condition.

- The reclose process can be controlled independently, which provides increased controllability and flexibility.

- External fault detection can also be brought in if necessary to provide full control of the operation. The vacuum interrupter can be triggered by both automatic superconductor quench or by external fault detection.

The disadvantages are: 
- An external power supply is needed for actuator operation. Harvesting energy from the HVDC network is a quite challenge.

- Fault detection, trigger signals and an interface circuit are required to control the actuator.

\subsection{AC SFCL integrated with vacuum interrupter system}

Separating the actuator supply from the fault current provides the greatest system operational flexibility. An AC SFCL integrated with a vacuum interrupter was investigated experimentally at the University of Manchester [13, 14]. The potential of a fast-acting actuator whose operation is independent from the fault current level and can also be latched in the open/closed position was investigated. The detailed system operation is presented in Figure 7. This system includes a superconductor coil in series with a mechanical switch, and then in parallel with an external bypass resistor. During a fault, a voltage develops naturally across the superconductor coil when it transitions to a normal conductor. The magnitude of the coil voltage was compared with a pre-set threshold voltage and used to automatically trigger the vacuum interrupter actuator. It is important to design and build a fast-acting actuator to operate the commercial DVS10CB vacuum interrupter used here. A moving coil actuator was selected and designed to provide controllable and high speed operation. Permanent magnet latches were used to hold the vacuum interrupter in the open and closed positions. This fast-acting vacuum interrupter actuator demonstrated successful operation opening the vacuum interrupter within 3 milliseconds.

A full-bridge DC-DC converter was used to control the moving coil actuator. The polarity of the output voltage and current can be controlled to allow the opening and closing of the actuator. The permanent magnet then latched the actuator in the open or closed positions without consuming any energy. The DC bus capacitor was pre-charged using a DC power supply or rectified line voltage, to provide the energy required to open and close the vacuum interrupter.

The method to determine whether the SFCL coil has quenched or not, was to compare the coil voltage with the pre-set threshold voltage level. When a fault occurred, the coil started to quench and the amplitude of the voltage across the coil increased quickly, exceeding the pre-set threshold voltage level. This then generated a signal to open the vacuum interrupter. The voltage across the coil however was sinusoidal in an AC system and therefore an absolute value circuit was needed to convert it into a positive output signal. A precision full-wave rectifier circuit was used. The absolute value of the coil voltage was compared with the pre-set threshold voltage level using a single voltage comparator. The pre-set threshold voltage level, which was connected to the positive input of voltage comparator, could be adjusted by a potentiometer. The trigger circuit, which was based on using a threshold value for the coil voltage, enables automatic operation without nuisance tripping or dependence on the fault current level. The ability to modify the pre-set threshold voltage also allows additional control functionality for the unit.

This system demonstrated successful operation during fault operation demonstrating repeatable behaviour at different potential peak currents. This confirmed that the fault current level did not affect the operation of the vacuum interrupter [14]. These practical experimental experiences are useful in developing the DC circuit breaker.

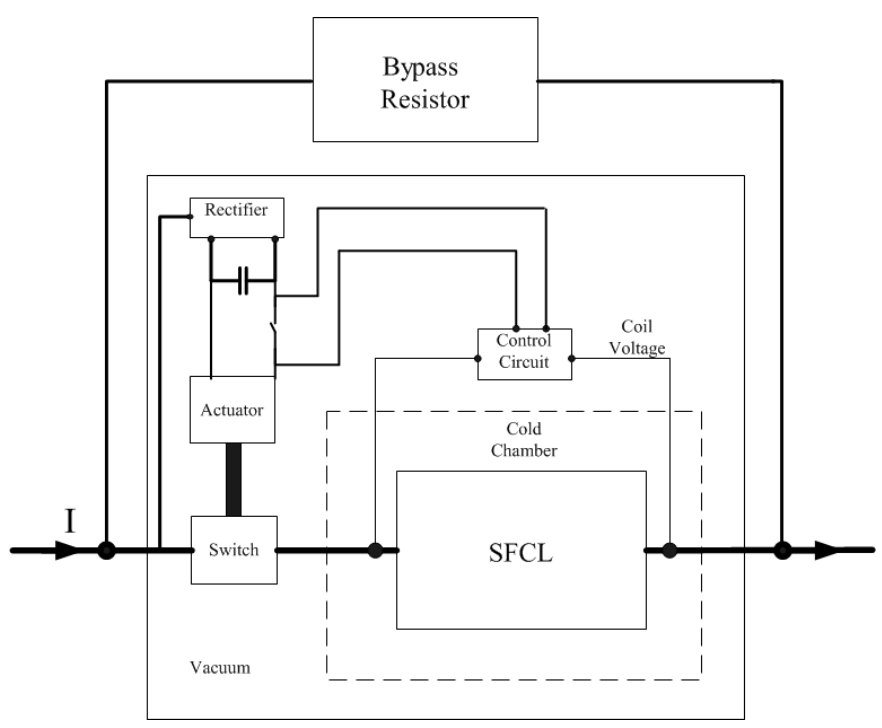

Figure 7: AC SFCL integrated with a vacuum interrupter system operation

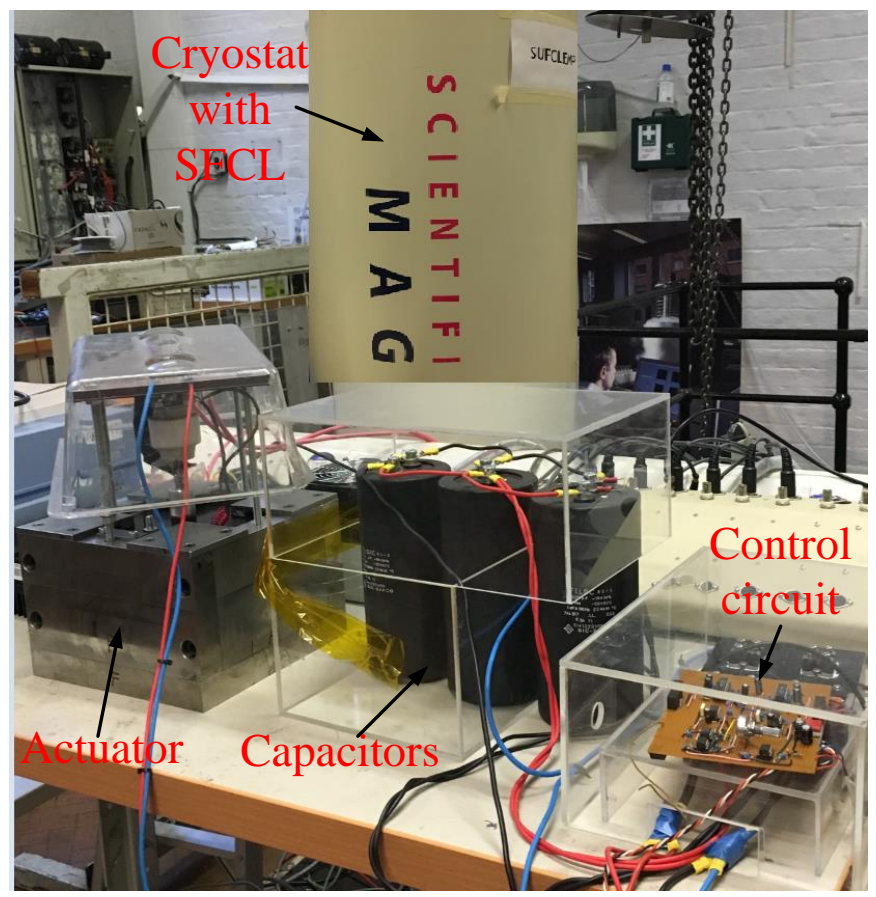

Figure 8: AC SFCL integrated with a vacuum interrupter test rig 


\section{High voltage connection}

The experimental tests were carried out at low voltage. To design the interface for a high voltage DC circuit breaker for HVDC transmission systems, the voltage across the superconductor could be similar in magnitude to the HVDC transmission voltage rating after the superconductor quenches. Practical solutions will be discussed in this section including the high voltage connection between the superconductor voltage and the control system. A control strategy will also be discussed for the superconducting DC circuit breaker.

A compensated resistive voltage divider (RC-divider) can be used to transform the high voltage to an intermediate/low voltage level for measurement purpose. Figure 9 shows a typical RC-divider and options for processing the output voltage signal. The primary side of the RC-divider is connected to the superconductor terminals. The output voltage signal can be processed and then used for the DC circuit breaker control.

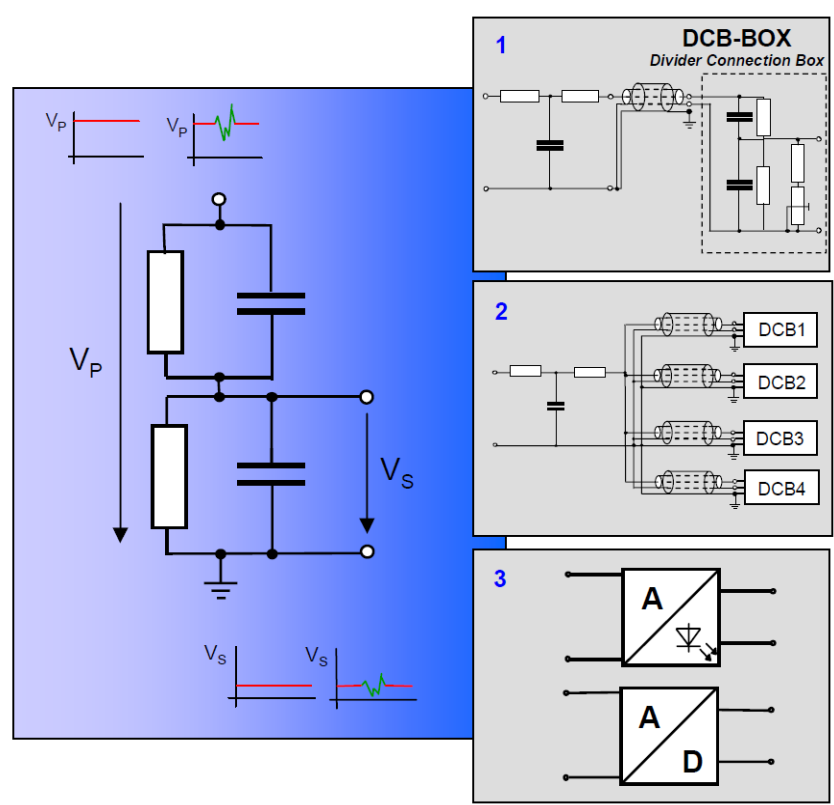

Figure 9: HVDC voltage divider [15]

There are three options for voltage signal processing depending on the application and transmission distance. The first option: the primary voltage is divided to an intermediate voltage. A double shielded cable is used to transmit the signal to the divider connection box (DCB-Box). The DCB-Box then divides the intermediate voltage to the secondary voltage. This voltage signal can then be transmitted over long distances and can also be protected against electromagnetic interference.

The second option: again the primary voltage is divided to an intermediate voltage. Several DCB-Boxes divide the intermediate voltage to different secondary voltage outputs for independent data processing or redundant paths. This method has the same advantages as the first option but also provides multiple independent measurement of the input voltage. The capital cost however is the highest among all the three options.

The third option: the primary voltage is directly divided to a secondary voltage. This secondary voltage can then be converted to a digital or optical signal. This is suitable for short distances with individual transforming, transmitting and analysing of the secondary signal. The third option is chosen here because the DC circuit breaker is a single unit and the superconductor coil is designed to be placed close to the other elements in the unit and the control system.

Galvanic isolation is desirable and often essential in measurement systems. Operator safety and signal quality are ensured with isolated interconnections. The ground for the superconductor may not be the same as the control system; it is necessary therefore to isolate the voltage signal. Isolation amplifiers, linear optocouplers or optical fibres can be sued for isolated connections.

A proposed control strategy for the superconducting DC circuit breaker is shown in Figure 10. A microcontroller is used to monitor the current, voltage and fault signals and also send control signals to the mechanical switch and semiconductor. The current signals fedback to the microcontroller include the total current through the circuit breaker, the current through the mechanical switch and the semiconductor. The voltage of the superconductor is connected to the primary side of the voltage divider. The output of the voltage divider is then connected to the control circuit and microcontroller through an isolation integrated circuit chip. An actuator control circuit monitors the superconductor coil voltage and the external fault detection signal, and then controls the mechanical switch. This DC circuit breaker and control system ensures great controllability and flexibility. A $10 \mathrm{kV}$ DC prototype circuit breaker will be built and tested based on this control strategy.

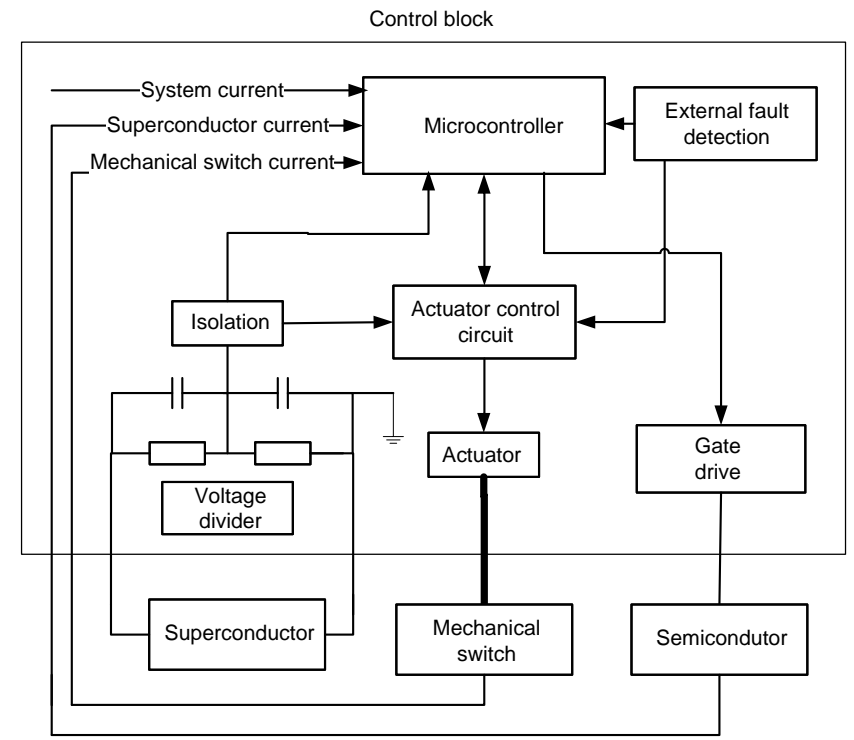

Figure 10: DC circuit breaker control diagram 


\section{Conclusions}

A superconducting DC circuit breaker is a potential solution for fault current management in MTDC networks. A mechanical switch controlled by a separate actuator is preferred due to its controllability and flexibility.

Practical problems such as high voltage connections are also considered. A suitable control strategy is also suggested for the superconducting DC circuit breaker. External fault detection can also be brought in if necessary to provide full control of the operation of the DC circuit breaker. The vacuum interrupter trigger signals include measurements of the overvoltage on the superconductor coil and detected fault signals in the power network. A prototype $10 \mathrm{kV}$ DC circuit breaker is to be developed based on the proposed control strategy.

\section{Acknowledgements}

This work was funded as part of the UK EPSRC, FCL/CB: An Integrated VSC-HVDC Fault Current Limiter/Breaker project, EP/L021552/1.

\section{References}

[1] Department of energy and climate change, "UK Renewable Energy Roadmap: 2013 update", https://www.gov.uk/government/uploads/system/upload s/attachment_data/file/255182/UK_Renewable_Energy_ Roadmap_-_5_November__FINAL_DOCUMENT_FOR_PUBLICATIO__.pdf."

[2] CIGRE Working Group B4-52, "HVDC grid feasibility study," CIGRE Brochure 533, Apr. 2013.

[3] M. Barnes and A. Beddard, "Voltage Source Converter HVDC Links - The state of the Art and Issues Going Forward”, Energy Procedia, vol. 24, 2012, pages: 108122.

[4] C. M. Franck, "HVDC Circuit Breakers: A Review Identifying Future Research Needs," IEEE Transactions on Power Delivery, vol. 26, no. 2, pp. 998-1007, April 2011.

[5] J. Häfner, B. Jacobson, "Proactive Hybrid HVDC Breakers - A key innovation for reliable HVDC grids," Cigré Bologna, 2011)

[6] C. C. Davidson, R. S. Whitehouse, C. D. Barker, J-P. Dupraz , W. Grieshaber, "A new ultra-fast HVDC Circuit breaker for meshed DC networks," 11th IET International Conference on AC and DC Power Transmission, Feb. 2015.

[7] B. Xiang, Z. Liu, Y. Geng, and S. Yanabu, "DC circuit breaker using superconductor for current limiting", IEEE Trans. Appl. Supercond., vol. 25, no. 2, Apr. 2015, 5600207.

[8] T. Hori, A. Otani, K. Kaiho, I. Yamaguchi, M. Morita, and S. Yanabu, "Study of superconducting fault current limiter using vacuum interrupter driven by electromagnetic repulsion force for commutating switch," IEEE Trans. Appl. Supercond., vol. 16, pp. 1999-2004, Jun. 2006.

[9] M. Endo, T. Hori, K. Koyama, I. Yamaguchi, K. Arai, K. Kaiho, and S. Yanabu, "Operating characteristics of superconducting fault current limiter using $24 \mathrm{kV}$ vacuum interrupter driven by electromagnetic repulsion switch," J. of Phys.: Con. Ser., vol. 97, 012068, 2008.

[10] EPRI, "Superconducting Fault Current Limiters", 1017793, 2009.

[11] O. B. Hyun, J. Sim, H. R. Kim, K. B. Park, S. W. Yim, and I. S. Oh, "Reliability enhancement of the fast switch in a hybrid superconducting fault current limiter by using power electronic switches," IEEE Trans. Appl. Supercond., vol. 19, pp. 1843-1846, Jun. 2009

[12] B. I. Jung and H. S. Choi, "Combined effect of the SFCL and solenoid coils," IEEE Trans. Appl. Supercond., vol. 24, 5600404, Jun. 2014.

[13] X. Pei, "Superconducting fault current limiter with integrated vacuum interrupter", The University of Manchester, 2012.

[14] X. Pei , A. C. Smith, R. Shuttleworth, "Experimental tests of a resistive SFCL integrated with a vacuum interrupter", 12th European Conference on Applied Superconductivity, Oct. 2015.

[15] Trench, "HVDC Divider: Compensated voltage divider for HVDC transmission systems", Mar, 2012. 